\title{
Stereoselective synthesis of trans-fused iridoid lactones and their identification in the parasitoid wasp Alloxysta victrix, Part II: Iridomyrmecins
}

Robert Hilgraf, Nicole Zimmermann, Lutz Lehmann, Armin Tröger and Wittko Francke*

\author{
Full Research Paper \\ Address: \\ Department of Chemistry - Organic Chemistry, University of Hamburg, \\ Martin-Luther-King-Platz 6, D-20146 Hamburg, Germany \\ Email: \\ Wittko Francke ${ }^{*}$ - francke@chemie.uni-hamburg.de \\ * Corresponding author \\ Keywords: \\ Alloxysta victrix; identification; iridoid; stereoselective synthesis; \\ trans-fused iridomyrmecin
}

Open Access

\author{
Beilstein J. Org. Chem. 2012, 8, 1256-1264. \\ doi:10.3762/bjoc.8.141 \\ Received: 16 March 2012 \\ Accepted: 20 July 2012 \\ Published: 08 August 2012 \\ This article is part of the Thematic Series "Biosynthesis and function of \\ secondary metabolites". Part I [1] describes the synthesis of \\ dihydronepetalactones by this approach. \\ Guest Editor: J. S. Dickschat \\ (c) 2012 Hilgraf et al; licensee Beilstein-Institut. \\ License and terms: see end of document.
}

\begin{abstract}
Following our earlier approach to the synthesis of dihydronepetalactones, all eight stereoisomers of trans-fused iridomyrmecins were synthesized starting from the enantiomers of limonene. Combined gas chromatography and mass spectrometry including enantioselective gas chromatography revealed that volatiles released by the endohyperparasitoid wasp Alloxysta victrix contain $(4 S, 4 \mathrm{a} R, 7 S, 7 \mathrm{a} R)$-iridomyrmecin of $95-97 \%$ ee and stereochemically pure $(4 S, 4 \mathrm{a} S, 7 R, 7 \mathrm{a} S)$-iridomyrmecin as a minor component.
\end{abstract}

\section{Introduction}

In the course of our studies on volatile signals of the endohyperparasitoid wasp, Alloxysta victrix, we identified several acyclic terpenoids and the trans-fused $(4 S, 4 \mathrm{a} R, 7 R, 7 \mathrm{a} S)$-dihydronepetalactone $(\mathbf{X})$ as volatile components of cephalic secretions released by this species (Figure 1) [1,2]. However, gas chromatograms showed the presence of two additional major volatiles $\mathbf{Y}$ and $\mathbf{Z}$ which, according to their mass spectra, were suggested to be trans-fused iridomyrmecins $[3,4]$. Since no synthetic reference compounds were available, all eight trans-fused iridomyrmecins had to be prepared. To complete the synthesis of this suite, we started from optically active limonene following a strategy similar to our route leading to trans-fused dihydronepetalactones [1]. The realization of this task and the unambiguous structure assignment of the natural products $\mathbf{Y}$ and $\mathbf{Z}$ is subject of the present paper.

\section{Results and Discussion}

Upon coupled gas chromatography/mass spectrometry (GC/MS), two major components, $\mathbf{Y}$ and $\mathbf{Z}$, of the volatile secretions of both sexes of Alloxysta victrix (although in much 
<smiles>C[C@H]1CC[C@@H](C)[C@H]2COC(=O)[C@@H]12</smiles>

$(4 R, 4 \mathrm{a} R, 7 R, 7 \mathrm{a} S)-4,7-$ dimethylhexahydrocyclopenta[c]pyran$1(3 H)$-one

$\mathbf{X}$

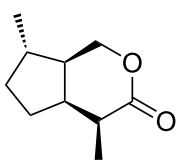

$(4 S, 4 a S, 7 S, 7 a R)-4,7-$ dimethylhexahydrocyclopenta[c]pyran$3(1 H)$-one

$$
1
$$

iridomyrmecin

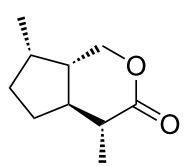

$(4 R, 4 a$ S $, 7 S, 7$ a $S)-4,7$ dimethylhexahydrocyclopenta[c]pyran$3(1 H)$-one

2

isoepiiridomyrmecin
Figure 1: Structures of cis- and trans-fused iridoid lactones.

higher amounts in males) gave almost identical $70 \mathrm{eV}$ EI-mass spectra (Figure 2); somewhat resembling that of the trans-fused dihydronepetalactone that we had already found in the insects [1]. Gas chromatography coupled with chemical ionization mass spectrometry (GC/CIMS) proved the molecular mass of the target compounds to be $[\mathrm{M}]^{+}=168$, while high resolution mass spectrometry (GC/HRMS) showed their atomic composition to be $\mathrm{C}_{10} \mathrm{H}_{16} \mathrm{O}_{2}$, confirming the compounds to be isomers of dihydronepetalactone. Though the fragmentation pattern showed some similarities to that of the cis-fused iridomyrmecin (1), a comparison with mass spectral data published for the trans-fused isoepiiridomyrmecin (2) suggested that the substances $\mathbf{Y}$ and $\mathbf{Z}$ are trans-fused iridomyrmecins. While the plotted mass spectrum of $\mathbf{1}$ showed $\mathrm{m} / \mathrm{z} 95$ as the base peak and similar abundances of about $55 \%$ for $\mathrm{m} / \mathrm{z} 67, \mathrm{~m} / \mathrm{z} 81$ and $\mathrm{m} / \mathrm{z}$ 109 [3], the data of 2 refer to $m / z 81$ as the base peak and $m / z 95$ and $\mathrm{m} / \mathrm{z} 109$ to reach $48 \%$ and $33 \%$, respectively [4]; this is more close to the spectra of $\mathbf{Y}$ and $\mathbf{Z}$ (Figure 2).

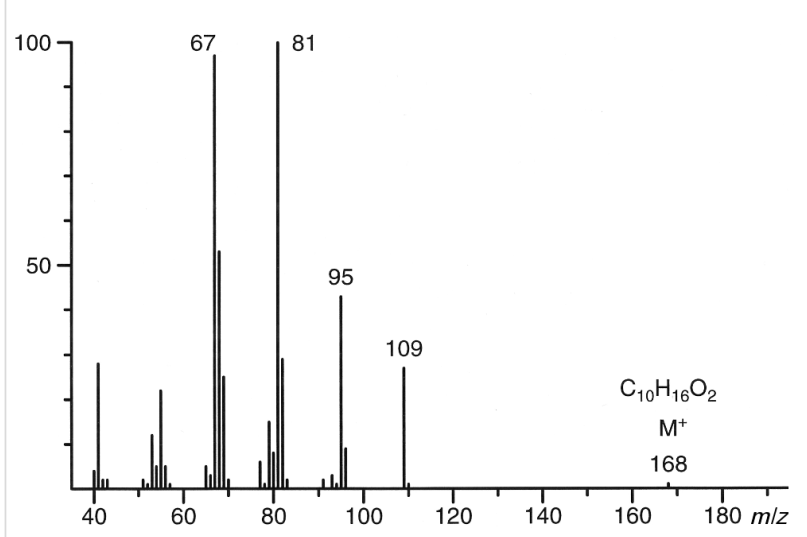

Figure 2: $70 \mathrm{eV} \mathrm{El-mass} \mathrm{spectrum} \mathrm{of} \mathrm{compounds} \mathbf{Y}$ and $\mathbf{Z}$ of Alloxysta victrix.

Iridomyrmecin (1) was first isolated from ants (Figure 1) [5] and along with some other volatile iridoids it has since been reported to be a potent insecticide and antibiotic from several natural sources [6]. Due to their challenging molecular structures and their interesting physiological properties, iridomyrmecins are attractive targets in stereoselective synthesis.

Similar to dihydronepetalactones, the iridomyrmecin skeleton shows four contiguous stereogenic centers giving rise to four trans-fused stereoisomers $\mathbf{A}-\mathbf{D}$ and four corresponding enantiomers $\mathbf{A}^{\prime}-\mathbf{D}$ ' (Figure 3, D' is identical to $\mathbf{2}$ in Figure 1). The presence of the four chiral centers complicates a stereoselective synthesis despite the small size of the molecule. Several methods have been published for the preparation of optically active cis-fused bicyclic iridoid lactones [7-10], whereas only a few syntheses of trans-fused ring systems have been reported [11]. Starting from enantiomerically pure $(R)$-pulegone, mixtures of $(7 R)$-configured diastereomers $\mathbf{A}^{\prime}$ and $\mathbf{B}^{\prime}$ as well as $\mathbf{C}$ and $\mathbf{D}$ have been synthesized by Wolinsky [12]. The set of stereochemically pure $(7 S)$-configured, trans-fused iridomyrmecins A, B, $\mathbf{C}^{\prime}$, and $\mathbf{D}^{\prime}$ has been prepared by Trave [13]. Though Wolinky's route may generally be used for the synthesis of all eight stereoisomers of trans-fused iridomyrmecins, it suffers from several major disadvantages such as high costs of $(S)$-pulegone and difficult separations of diastereomeric mixtures.

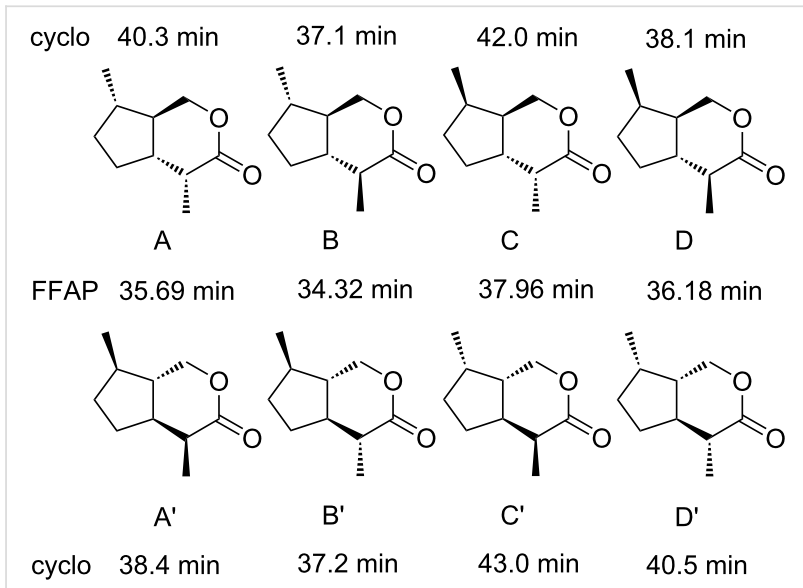

Figure 3: Chemical structures of all eight stereoisomers of trans-fused iridomyrmecins and their gas chromatographic retention times (min) on FFAP and on a cyclodextrin column (cyclo). For experimental details see Supporting Information File 1.

Starting from the cheaply available pure enantiomers of limonene, we had reported a novel stereoselective route towards trans-fused dihydronepatalactones [1] which we now extended to the synthesis of all eight stereoisomers of trans-fused iridomyrmecins. Subsequently, the volatile components $\mathbf{Y}$ and $\mathbf{Z}$ - present in Alloxysta victrix - were confirmed to be transfused iridomyrmecins, and their absolute configurations could be determined by comparison of their analytical data with those of all eight synthetic stereoisomers. 


\section{Synthesis of trans-fused iridomyrmecins}

Our approach to the eight trans-fused iridomyrmecins starting from the enantiomers of limonene followed our general route for the synthesis of trans-fused dihydronepetalactones (Figure 4) [1].

Starting from pure $(R)$-limonene (3), the key intermediate 4 was prepared as described previously [1] and was used for both the synthesis of trans, trans and cis,trans (these designations refer to the relative configurations between the methyl group at $\mathrm{C}-7$ and the substitution pattern at C-7a and C-4a, respectively) configured iridomyrmecins. Key steps were two stereoselective hydrogenations: A transfer hydrogenation for a formal "anti" delivery of hydrogen $[14,15]$, as represented in $\mathbf{5}$, and the use of Crabtree's catalyst in a directed hydrogenation for a "syn" addition of hydrogen as represented in 6 [16-18]. Subsequent to the hydrogenation step, the synthesis of trans-fused iridomyrmecins could be completed after some standard functional group modifications. The synthesis of the corresponding enantiomers followed the same way, starting from (S)-limonene (3').

\section{Synthesis of trans-fused iridomyrmecins A and B}

The aldehyde $\mathbf{8}$, derived from $(R)$-limonene (3), served as the key intermediate for the synthesis of the trans-fused iridomyrmecins A and B (Scheme 1). As shown in the stereo-

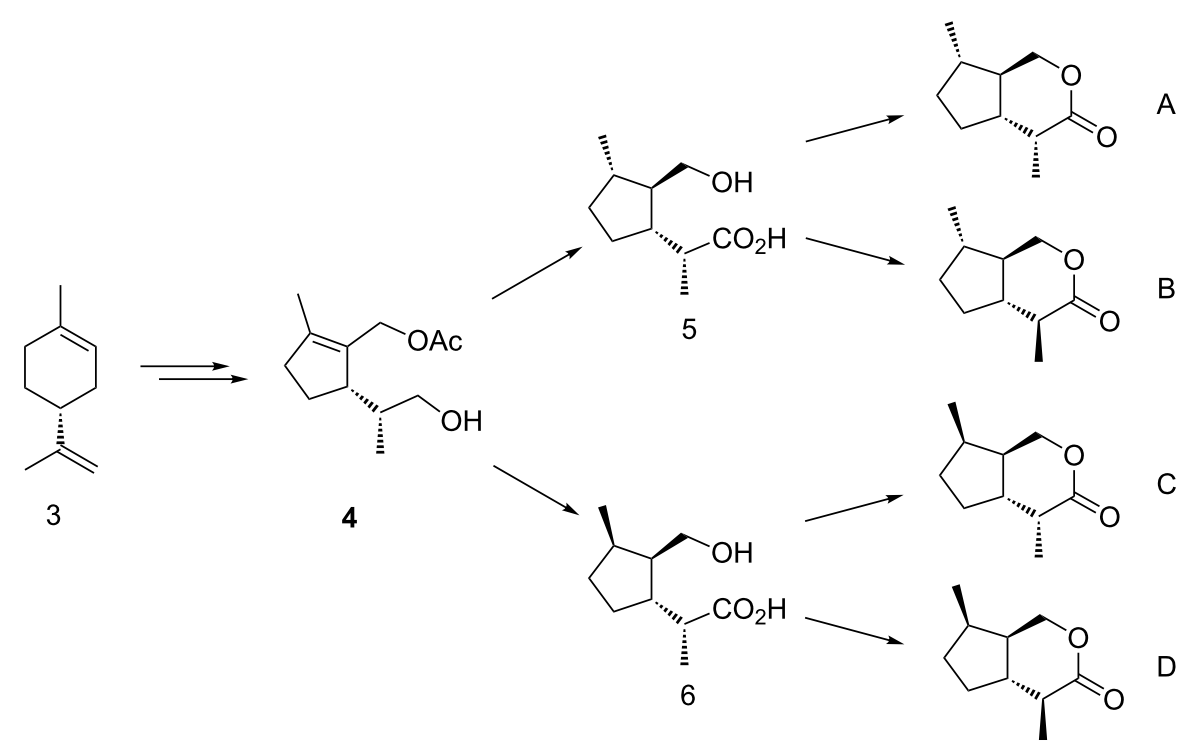

Figure 4: Strategy for the stereoselective synthesis of trans-fused iridomyrmecins A-D from $(R)$-limonene.

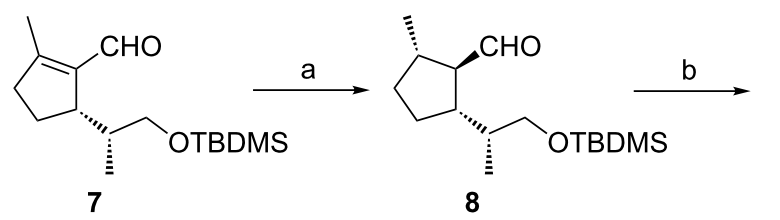<smiles>C[C@H]1CCC[C@@H]1COCc1ccccc1</smiles>

11

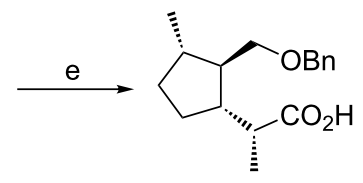

12<smiles>C[C@@H]1CC[C@H]([C@@H](C)CO[R16](C)(C)C)[C@H]1CO</smiles>

9<smiles>CCC(C)CC</smiles>

5<smiles>C[C@H](C(=O)O)[C@H]1CC[C@@H](C)[C@@H]1CO</smiles><smiles>C[C@H](OCc1ccccc1)[C@H](C)COCc1ccccc1</smiles>

d<smiles>C[C@H]1CC[C@H]2C(COC(=O)[C@H](C)[C@@H]2C)[C@@H]1C</smiles>

A

B

Scheme 1: Synthesis of the trans-fused iridomyrmecins $\mathbf{A}$ and $\mathbf{B}$. Reaction conditions and yields: a) ammonium formate, $\mathrm{Pd} / \mathrm{C}, \mathrm{MeOH}$, reflux (48\%); b) $\mathrm{NaBH}_{4}, \mathrm{MeOH}, \mathrm{H}_{2} \mathrm{O}$, rt (79\%); c) $\mathrm{NaH}, \mathrm{BnBr}$, THF, reflux (96\%); d) HF, $\mathrm{CH}_{3} \mathrm{CN}$, rt (71\%); e) $\mathrm{CrO}_{3}, \mathrm{H}_{2} \mathrm{SO}_{4}$, acetone, rt (99\%); f) $\mathrm{Pd} / \mathrm{C}, 40$ bar $\mathrm{H}_{2}$, THF, rt (100\%); g) DCC, DMAP, $\mathrm{CH}_{2} \mathrm{Cl}_{2}$, rt (66\%); h) $p$-TsOH, benzene, reflux (56\%). 
selective synthesis of trans-fused dihydronepetalactones [1], this key intermediate could be obtained via a highly diastereoselective transfer hydrogenation of the known [19] trisubstituted cyclopentene 7 with ammonium formate over palladium $[1,14,15]$. Starting from the aldehyde $\mathbf{8}$, the relative configuration of which had been confirmed by NOE experiments [1], the synthesis of $\mathbf{A}$ and $\mathbf{B}$ was completed in six additional steps.

First, the aldehyde $\mathbf{8}$ was reduced with sodium borohydride, and the resulting alcohol 9 was protected as the benzyl ether to form 10. Deprotection of the TBDMS ether was carried out with HF in acetonitrile to yield the mono-protected diol 11. Using Jones reagent, the free hydroxy group of $\mathbf{1 1}$ was oxidized to the carboxylic acid 12, and the benzyl ether was cleaved upon catalytic hydrogenation over $\mathrm{Pd} / \mathrm{C}$ to produce the hydroxy acid 5. The latter served as the immediate precursor for the formation of either of the two diastereomeric iridomyrmecins $\mathbf{A}$ and B: Careful cyclization using dicyclohexylcarbodiimide (DCC) and 4-dimethylaminopyridine (DMAP) in dichloromethane at $\mathrm{rt}$ afforded iridomyrmecin A. In contrast, treatment of $\mathbf{5}$ with catalytic amounts of $p$-toluenesulfonic acid in benzene under reflux conditions for $12 \mathrm{~h}$ resulted in a complete epimerization at the $\mathrm{CH}$-acidic $\mathrm{C}-4$ position, exclusively yielding the thermodynamically more stable iridomyrmecin $\mathbf{B}$. All reaction steps were also carried out starting from enantiomerically pure $(S)$ limonene affording trans-fused iridomyrmecins $\mathbf{A}^{\prime}$ and $\mathbf{B}^{\prime}$. Relative configurations of iridomyrmecins $\mathbf{A}, \mathbf{A}^{\prime}$ and $\mathbf{B}, \mathbf{B}^{\prime}$ were confirmed by NOESY experiments. In A (Figure 5, A) decisive NOEs could be observed between $1-\mathrm{Hb}$ and $4 \mathrm{a}-\mathrm{H}$ as well as between $1-\mathrm{Hb}$ and $7-\mathrm{H}$ which showed $4 \mathrm{a}-\mathrm{H}$ and $7-\mathrm{H}$ to be located at the same side of the molecule. In addition, NOEs between $4-\mathrm{CH}_{3}$ and $7 \mathrm{a}-\mathrm{H}$ as well as between $7-\mathrm{CH}_{3}$ and $7 \mathrm{a}-\mathrm{H}$ proved the two methyl groups to be located at the same side of the molecule. In contrast, as shown in Figure 5, B', NOEs between $4-\mathrm{H}$ and $7 \mathrm{a}-\mathrm{H}$ as well between $7-\mathrm{CH}_{3}$ and $7 \mathrm{a}-\mathrm{H}$, prove that in $\mathbf{B}^{\prime}$ the two methyl groups are situated at opposite sides of the molecule.

\section{Synthesis of trans-fused iridomyrmecins C and $\mathbf{D}$}

As shown in our previous paper on the synthesis of trans-fused dihydronepetalactones, the double bond of the acetate 4 could be hydrogenated with high stereocontrol to the diastereomerically pure acetate 13 [1] by using Crabtree's catalyst [16-18]. The synthesis of the iridomyrmecins $\mathbf{C}$ and $\mathbf{D}$ was completed in three additional steps (Scheme 2). The oxidation with Jones reagent yielded 14, and subsequent saponification of the acetate group with methanolic $\mathrm{KOH}$ afforded the hydroxy acid $\mathbf{6}$. Similar to the approach described above, careful lactonization with DCC and DMAP gave iridomyrmecin $\mathbf{C}$, whereas treatment with $p$-toluenesulfonic acid in benzene under reflux conditions led to complete epimerization at $\mathrm{C}-4$ and afforded iridomyrmecin D. All reaction steps were also carried out starting from enantiomerically pure $(S)$-limonene $\left(\mathbf{3}^{\prime}\right)$ and afforded iridomyrmecins $\mathbf{C}^{\prime}$ and $\mathbf{D}^{\prime}$.

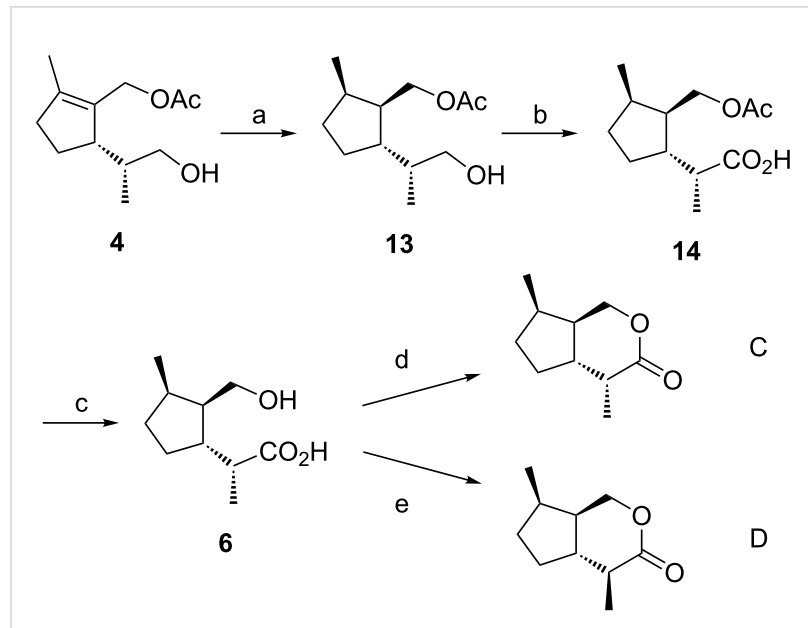

Scheme 2: Synthesis of the trans-fused iridomyrmecins $\mathbf{C}$ and $\mathbf{D}$. Reaction conditions and yields: a) Crabtree's catalyst [ $\left.\operatorname{lr}(\mathrm{cod}) \mathrm{PCy}_{3}(\mathrm{py})\right] \mathrm{PF}_{6}(10 \mathrm{~mol} \%), 1$ bar $\mathrm{H}_{2}, \mathrm{CH}_{2} \mathrm{Cl}_{2}$, rt (81\%); b) $\mathrm{CrO}_{3}$, $\mathrm{H}_{2} \mathrm{SO}_{4}$, acetone, rt (86\%); c) $\mathrm{KOH}, \mathrm{MeOH}$, rt (97\%); d) DCC, DMAP, $\mathrm{CH}_{2} \mathrm{Cl}_{2}$, rt (41\%); e) $p$ - TsOH, benzene, reflux (59\%).
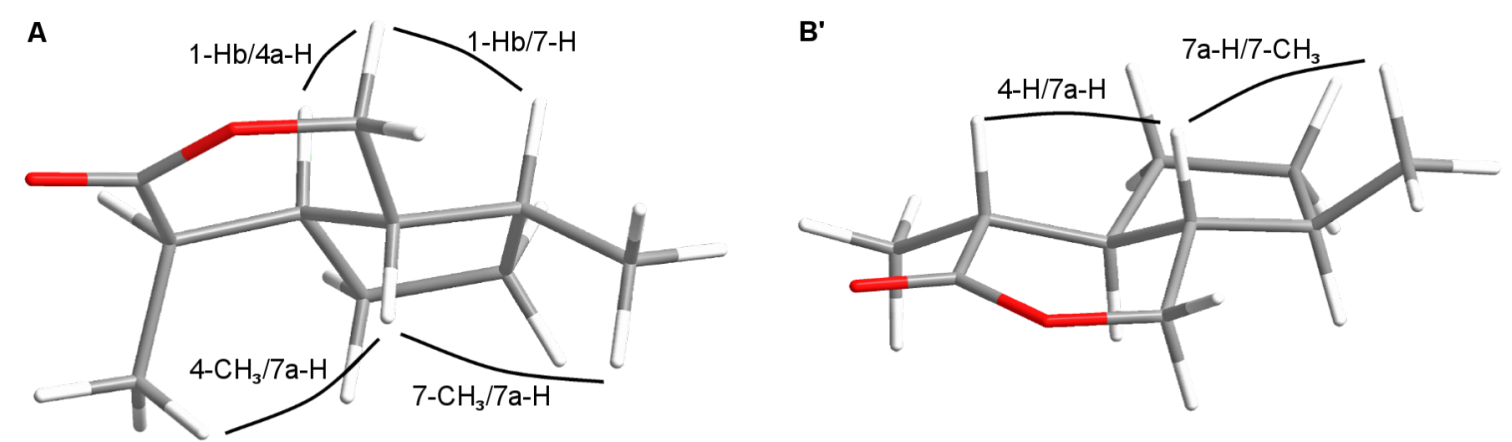

Figure 5: Configurations of the trans-fused iridomyrmecins A and B'. 
Relative configurations of the iridomyrmecins $\mathbf{C}, \mathbf{C}^{\prime}$ and $\mathbf{D}, \mathbf{D}^{\prime}$ were confirmed by NOESY experiments. In $\mathbf{C}$ (Figure 6, C) decisive NOEs between $1-\mathrm{Hb}$ and $4 \mathrm{a}-\mathrm{H}$ as well as between $1-\mathrm{Hb}$ and $7-\mathrm{CH}_{3}$ proved $4 \mathrm{a}-\mathrm{H}$ and $7-\mathrm{CH}_{3}$ to be located at the same side of the molecule. The NOE between $4-\mathrm{CH}_{3}$ and $7 \mathrm{a}-\mathrm{H}$ showed them to be geometrically close and the two methyl groups to be in opposite positions. In contrast, as shown in Figure 6, D' NOEs between $4 \mathrm{a}-\mathrm{H}$ and $4-\mathrm{CH}_{3}$ as well as between $4 \mathrm{a}-\mathrm{H}$ and $1-\mathrm{Hb}$ and furthermore between $1-\mathrm{Hb}$ and $7-\mathrm{CH}_{3}$ proved the methyl groups in $\mathbf{D}^{\prime}$ to be at the same side of the molecule. This is confirmed by a NOE between $4-\mathrm{H}$ and $7 \mathrm{a}-\mathrm{H}$.

In summary, we have completed the first enantioselective synthesis of all eight stereoisomers of trans-fused iridomyrmecins, starting from either of the cheaply available enantiomers of limonene. The acetate $\mathbf{4}$ is the decisive intermediate, and key reaction steps are two stereoselective hydrogenations: A transfer hydrogenation for a formal "anti" delivery of hydrogen and the use of Crabtree's catalyst in a directed hydrogenation for a "syn"-addition of hydrogen. Starting from pure enantiomers of limonene [1] these novel synthetic routes provided iridomyrmecins $\mathbf{A}, \mathbf{A}^{\prime}$ and $\mathbf{B}, \mathbf{B}^{\prime}$ in $2-3 \%$ yield over 15 steps as well as iridomyrmecins $\mathbf{C}, \mathbf{C}^{\prime}$ and $\mathbf{D}, \mathbf{D}^{\prime}$ in $10-15 \%$ yield over 9 steps.

All eight stereoisomers of trans-fused iridomyrmecins could be separated by gas chromatography using a capillary column coated with FFAP as an achiral polar stationary phase and a second capillary coated with a 1:1 mixture of OV1701 and heptakis(6-O-tert-butyldimethylsilyl-2,3-di- $O$-methyl)- $\beta$ cyclodextrin as an enantioselective stationary phase. Figure 3 shows the structures and retention times of all eight stereoisomers of trans-fused iridomyrmecins on both capillary column systems. Despite the small differences in retention times between B and B' on the cyclodextrin column, the enantiomers could be well distinguished under the experimental conditions.

\section{Structure assignment of volatile components $\mathbf{Y}$ and $\mathbf{Z}$ in the parasitoid wasp Alloxysta victrix}

Comparison of mass spectra and GC retention times of synthetic iridomyrmecins with corresponding data of the volatile substances $\mathbf{Y}$ and $\mathbf{Z}$ - which are present in pentane extracts of heads of Alloxysta victrix - allowed their unambiguous identification as trans-fused iridomyrmecins.

Coupled GC/MS analysis using FFAP as the stationary phase revealed the natural iridoid lactones $\mathbf{Y}$ and $\mathbf{Z}$ to show the same mass spectra and retention times as the two early eluting racemates of the synthetic iridomyrmecins, i.e., $\mathbf{B} / \mathbf{B}^{\prime}$ and $\mathbf{A} / \mathbf{A}^{\prime}$, respectively (Figure 3 ). Enantioselective gas chromatography on heptakis(6-O-tert-butyldimethylsilyl-2,3-di-O-methyl)- $\beta$ cyclodextrin showed that $\mathbf{A}$ and $\mathbf{A}^{\prime}$ were well separated with an $\alpha$-value of $\mathbf{A}: \mathbf{A}^{\prime}=1.05$ (Figure 3). Consequently, the structure of $\mathbf{Z}$ could be easily determined to be $\mathbf{A}^{\prime}$, namely $(4 S, 4 \mathrm{a} S, 7 R, 7 \mathrm{a} S)$-iridomyrmecin. Under the same experimental conditions, $\mathbf{B}$ and $\mathbf{B}^{\prime}$ ' were only poorly resolved, however, heptaiks(2,6-di- $O$-methyl-3-O-pentyl)- $\beta$-cyclodextrin produced a good $\alpha$-value of $\mathbf{B}^{\prime}: \mathbf{B}=1.015$ [20]. As a result, $\mathbf{Y}$ was unambiguously identified to be $(4 S, 4 \mathrm{a} R, 7 S, 7 \mathrm{a} R)$-iridomyrmecin. A careful inspection of the analytical data obtained with the cyclodextrin column revealed the presence of small amounts of $(4 R, 4 \mathrm{a} S, 7 R, 7 \mathrm{a} S)$-iridomyrmecin $\mathbf{B}^{\prime}$ in the natural extract, showing the ee of natural $\mathbf{B}$ to be ca. 95-97\%. Figure 7 shows a typical gas chromatogram (obtained with FFAP as the stationary phase) of an extract of heads of male $A$. victrix. Identified structures are assigned.

\section{Structural relations between the Alloxysta- compounds and other insect iridoids}

The iridoid lactones which are present in the cephalic secretions of Alloxysta victrix show an unusual trans-fusion. Among the compounds showing this structure, only the lactone $\mathbf{X}$ [1]

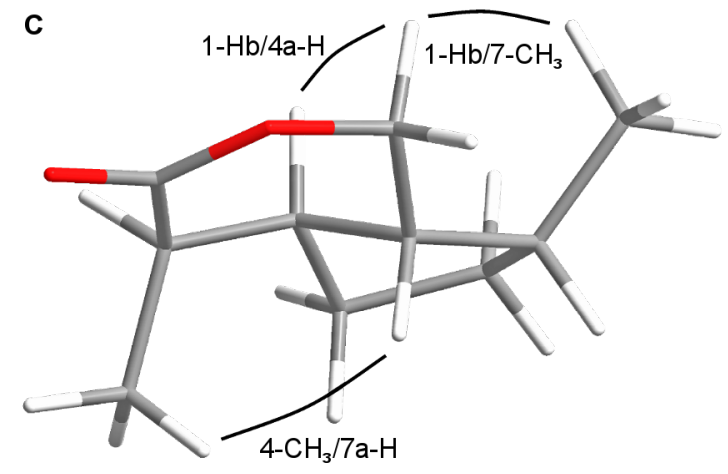

D'

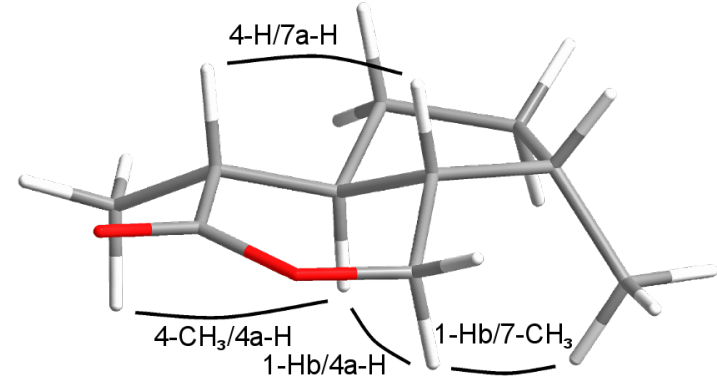

Figure 6: Configurations of the trans-fused iridomyrmecins C and D'. 


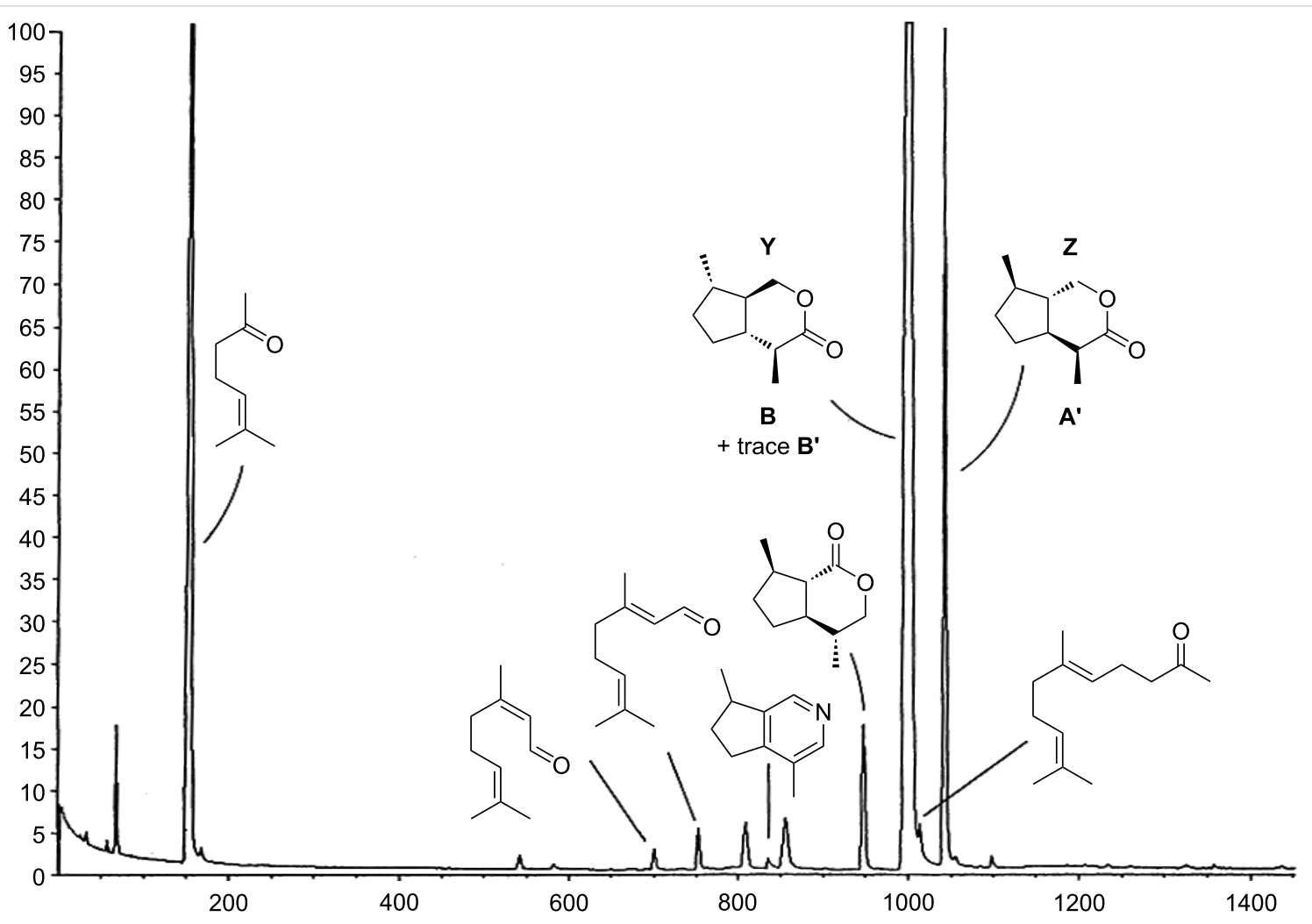

Figure 7: Volatile terpenoids in the cephalic secretion of Alloxysta victrix. For the identification of compounds other than $\mathbf{Y}$ and $\mathbf{Z}$ see [1].

(Figure 1) and a compound with the same relative configuration [21] have been described from insects so far. In contrast to that, the cis-fused nepetalactone $\mathbf{1 5}$ and diastereomers thereof are typical components of many species of the plant genus Nepeta [22,23]. Along with the corresponding hemiacetal 16, which shows $(1 R)$-configuration, $\mathbf{1 5}$ is also a most important sex pheromone of aphids [24] (Figure 8). Nevertheless, iridoids are usually associated with defense chemistry. Whilst configurations at the stereogenic centers of $\mathbf{1 5}$ and related iridoid lactones in insects appear to be stereotypic, several monocyclic iridoids show further stereochemical variation. Lactol 16 and iridodial (17) have first been identified as defense compounds of ants [25]. More recently, 17 - which shows $(R)$-configuration at $\mathrm{C} 1$ of the side-chain - was found to be a male-produced aggregation pheromone of lacewings [26,27].

The cis-fused iridomyrmecin (1) and dolichodial (18) are constituents of the anal gland secretion of the Argentine ant Iridomyrmex humilis [28]. More recently, $(1 S, 2 R, 3 S)$ dolichodial (18) has been identified as an electrophysiologically active volatile released from the rosy apple aphid Dysaphis plantaginea oviparae and has been discussed apart from $\mathbf{1 5}$ and $\mathbf{1 6}$ as a possible third component of the aphid sex pheromone [29]. Actually, 18 was first identified in the defensive secretions of dolichoderine ants [25]. The same substance

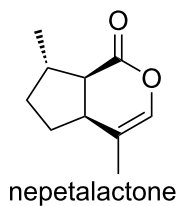

15<smiles>C=C(C=O)[C@H]1CC[C@@H](C)[C@H]1C=O</smiles>

dolichodial

18<smiles>CC1=C(C=O)[C@@H](C(C)C=O)CC1</smiles>

chrysomelidial

21

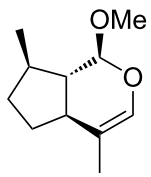

methoxymyodesertene

24

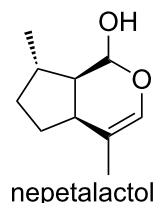

16

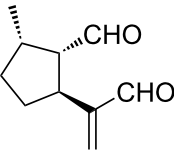

anisomorphal

19

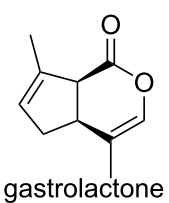

22

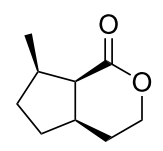

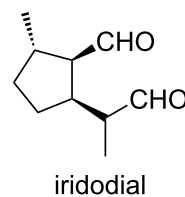

17

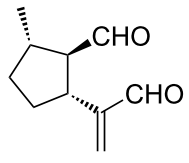

peruphasmal

20

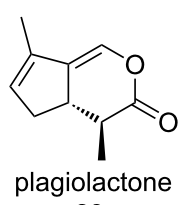

23

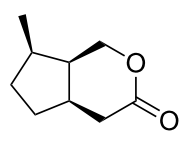

Figure 8: Structures of iridoids from insects and plants. Absolute configurations of 19 and 20 are "educated guesses". 
(or its enantiomer) has been found as a defensive compound of Nematine larvae [30] and in adults and larvae of the thrips Calloccithrips fuscipennis [31]. A stereoisomer of dolichodial anisomorphal (19) - is a component of the defensive secretion of the walking stick Anisomorpha buprestoides [32], whilst a third stereoisomer - peruphasmal (20) - has been identified in another walking stick, Peruphasma schultei [33,34]. Recent investigations show that the qualitative and quantitative composition of cyclopentanoid iridoids in the defensive secretion of A. buprestoides may vary with age and population. The secretion may contain all three isomers 18,19 and 20 which the insect can produce from glucose [35]. The absolute configurations of $\mathbf{1 9}$ and $\mathbf{2 0}$ are still unknown. It should be mentioned that along with other iridoids $\mathbf{1 8}$ and $\mathbf{1 9}$ are also components of the essential oil of some plant species [36]. A related cyclopentene derivative is chrysomelidial (21), a relatively widespread defense compound in larvae of phytophagous leaf beetles Chrysomelidae [37,38], which has been found in other insects, too. In the defensive secretion of oribatid mites it keeps the depicted $(5 S, 8 S)$-configuration [39]. In some species, chrysomelidial is accompanied by the dehydronepetalactone 22 (gastrolactone) [40] or the didehydroiridomyrmecin 23 (plagiolactone) [37]. To the best of our knowledge, the two iridomyrmecins $\mathbf{Y}$ and $\mathbf{Z}$ are new natural products, representing the first transfused iridoid lactones of this type.

Whilst the trans-fused nature of the new iridoid lactones is very unusual, their stereochemical pattern (Figure 7) is even more puzzling: The configurational arrangements of the substituents in $\mathbf{X}$ and $\mathbf{Y}$ are strictly opposite, whereas the relations between $\mathbf{X}$ and $\mathbf{Z}$ are relatively close, showing inversion at C-4 only. Strangely, $\mathbf{Z}$ is not the expected $\mathrm{C}-4$-epimer of $\mathbf{Y}$, but the C-4epimer of its enantiomer.

Apart from very few exceptions such as methoxymyodesertene (24) [41], the 4-nor-nepetalactone mitsugashiwalactone (25) [42] and its "nor-iridomyrmecin-complement" boschnialactone (26), [43] which all are plant volatiles, the methyl group in the typical five-membered ring of iridoids keeps its $(S)$-configuration (see also Figure 8), which is just in contrast to $\mathbf{X}$ and $\mathbf{Z}$ [44]. However, recently, two stereoisomers of iridomyrmecin showing (7R)-configuration have been reported to be components of the defense chemistry of the Drosophila parasitoid Leptopilina heterotoma [45].

\section{Remarks on the biosynthesis of iridoids}

Today it is generally accepted that the biosynthesis of iridoids starts from the acyclic geraniol (27). In a series of careful, elegant experiments it was shown that $\mathbf{2 7}$ is oxidized to 8 -hydroxygeraniol (28) which is further transformed to 8-oxogeranial (29) [46-48] (Figure 9).

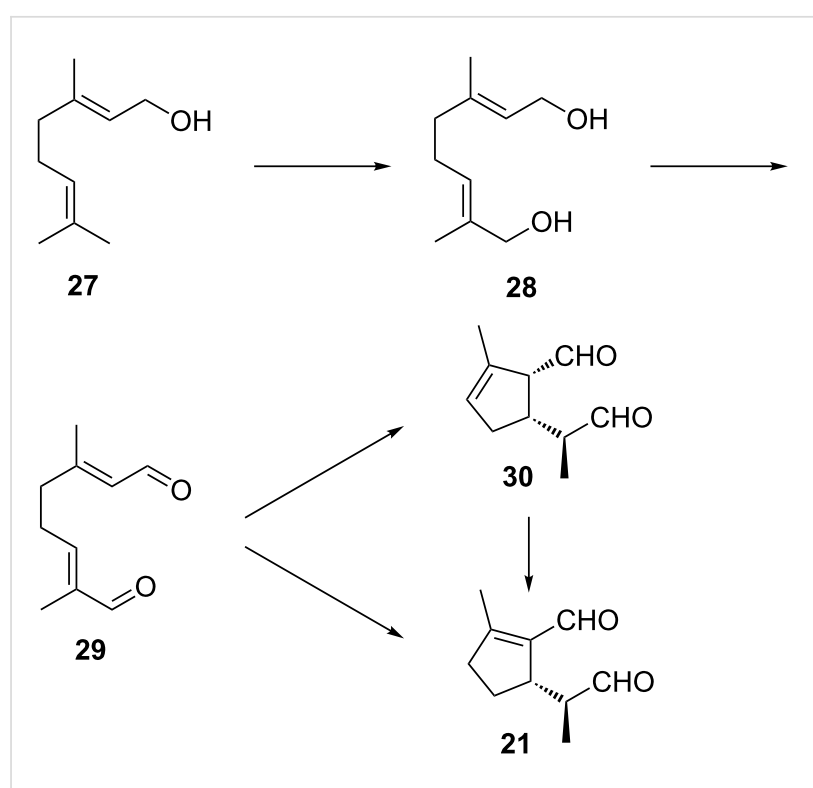

Figure 9: Biosynthetic ways to iridoids from geraniol.

During these investigations the stereochemistry of the subsequent cyclization to iridoids was found to be different in larvae of herbivorous leaf beetles and in carnivorous rove beetles. In Phaedon cochleariae (Chrysomelidae), cyclization of 29 directly affords chrysomelidial (21). In contrast, in Phylonthus sp. (Staphylinidae) the first step is the formation of plagiodial (30), which was first identified from larvae of several leaf beetle species $[49,50]$. Subsequently, 30 may rearrange to the thermodynamically more stable, conjugated 21. Despite these results, there are still a lot of open questions concerning the biosynthesis of iridoids. Recently, it could be shown that leaf beetles may produce iridoid monoterpenes de novo [33] but they are also able to sequester glycosidically bound terpene precursors from their food plants [51-53] which is highly interesting with regards to the evolution of insect-plant relationships and insect defense chemistry. At present, nothing is known about the formation of "saturated" iridoids such as iridodial (17) or the iridoid lactones in Alloxysta. The strange stereochemical relations between these compounds may well be the result of different mechanisms in the enzymatic hydrogenation steps.

\section{Conclusion}

The new iridoid lactones have been found in the mandibular gland secretions of several alloxystine wasps [54] and their activity in intraspecific and interspecific communication has been discussed [55]. According to first bioassays, the new iridoids seem to play a multifunctional role in the tritrophic system of the aphid Sitobion avenae, its parasite, the wasp Aphidius uzbekistanicus, and the hyperparasitoide Alloxysta victrix as they obviously sedate Sitobion and repell Aphidius. 
However, additional bioassays will be needed to better understand the biological significance of the newly identified iridoid lactones. As our way from limonene to iridoids provides relatively easy access to a large variety of iridoid lactones and monocyclic iridoids, behavior experiments using synthetic compounds may shed some more light on the complex relationships between host aphids, primary parasitoids such as Aphidius spp., and aphid hyperparasitoids such as Alloxysta spp. [56].

\section{Supporting Information}

\section{Supporting Information File 1}

Experimental details and characterization data for synthesized compounds.

[http://www.beilstein-journals.org/bjoc/content/ supplementary/1860-5397-8-141-S1.pdf]

\section{Acknowledgements}

The biological material used in this investigation was kindly provided by Prof. Dr. Urs Wyss, University of Kiel, Germany. Financial support by the German Science Foundation, Deutsche Forschungsgemeinschaft (DFG - Fr 12/1), is gratefully acknowledged.

\section{References}

1. Zimmermann, N.; Hilgraf, R.; Lehmann, L.; Ibarra, D.; Francke, W. Beilstein J. Org. Chem. 2012, 8, 1246-1255. doi:10.3762/bjoc.8.140

2. Petersen, G.; Matthiesen, C.; Francke, W.; Wyss, U. Eur. J. Entomol. 2000, 97, 545-550.

3. Regnier, F. E. In Biochemical Application of Mass Spectrometry; Waller, G. R., Ed.; Wiley \& Sons: New York, 1972; pp 723-734.

4. Sakai, T.; Nakajima, K.; Sakan, T. Bull. Chem. Soc. Jpn. 1980, 53, 3683-3686. doi:10.1246/bcsj.53.3683

5. Pavan, M. Ric. Sci. 1950, 20, 1853-1855.

6. Roth, L. M.; Eisner, T. Annu. Rev. Entomol. 1962, 7, 107-136. doi:10.1146/annurev.en.07.010162.000543

7. Thomas, A. F.; Bessière, Y. The Synthesis of Monoterpenes, 1980-1986. In The Total Synthesis of Natural Products; ApSimon, J. W., Ed.; Wiley-Interscience: New York, 1988; Vol. 7, pp 275-454. (and references cited therein).

8. Nangia, A.; Prasuna, G.; Bheema Rao, B. Tetrahedron 1997, 53, 14507-14545. doi:10.1016/S0040-4020(97)00748-5 (and literature cited therein).

9. Ernst, M.; Helmchen, G. Synthesis 2002, 1953-1955.

10. Beckett, J. S.; Beckett, J. D.; Hofferberth, J. E. Org. Lett. 2010, 12, 1408-1411. doi:10.1021/ol100077z (and references cited therein).

11. Sisido, K.; Inomata, K.; Kageyqama, T.; Utimoto, K. J. Org. Chem. 1968, 33, 3149-3155. doi:10.1021/jo01272a027

12. Wolinsky, J.; Gibson, T.; Chan, D.; Wolf, H. Tetrahedron 1965, 21, 1247-1261. doi:10.1016/0040-4020(65)80066-7

13. Trave, R.; Marchesini, A.; Garanti, L. Gazz. Chim. Ital. 1970, 100, 1061-1075.
14. Lange, G. L.; Neidert, E. E.; Orrom, W. J.; Wallace, D. J. Can. J. Chem 1978, 56, 1628-1633. doi:10.1139/v78-266

15. Rao, H. S. P.; Reddy, K. S. Tetrahedron Lett. 1994, 35, 171-174. doi:10.1016/0040-4039(94)88193-6

16. Crabtree, R. H.; Davis, M. W. Organometallics 1983, 2, 681-892. doi:10.1021/om00077a019

17. Crabtree, R. H.; Davis, M. W. J. Org. Chem. 1986, 51, 2655-2661. doi:10.1021/jo00364a007

18. Brown, J. M. Angew. Chem., Int. Ed. Engl. 1987, 26, 190-203. doi:10.1002/anie.198701901

19. Wolinsky, J.; Slabaugh, M. R.; Gibson, T. J. Org. Chem. 1964, 29 , 3740-3742. doi:10.1021/jo01035a537

20. Ibarra-Wiltschek, D. Identifizierung und Synthese mono- und sesquiterpenoider Inhaltsstoffe aus Hymenopteren. Ph.D. Thesis, Universität Hamburg, Germany, 1995.

21. Jefson, M.; Meinwald, J.; Nowicki, S.; Hicks, K.; Eisner, T. J. Chem. Ecol. 1983, 9, 159-180. doi:10.1007/BF00987779

22. Meinwald, J. J. Am. Chem. Soc. 1954, 76, 4571-4573. doi:10.1021/ja01647a018

23. Regnier, F. E.; Waller, G. R.; Eisenbraun, E. J. Phytochemistry 1967, 6, 1281-1289. doi:10.1016/S0031-9422(00)86090-2

24. Dawson, G. W.; Griffiths, D. C.; Merritt, L. A.; Mudd, A.; Pickett, J. A.; Wadhams, L. J.; Woodcock, C. M. J. Chem. Ecol. 1990, 16, 3019-3030. doi:10.1007/BF00979609

25. Cavill, G. W. K.; Hinterberger, H. Aust. J. Chem. 1961, 14, 143-149. doi:10.1071/CH9610143

26. Hooper, A. M.; Donato, B.; Woodcock, C. M.; Park, J. H.; Paul, R. L.; Boo, K. S.; Hardie, J.; Pickett, J. A. J. Chem. Ecol. 2002, 28, 849-864. doi:10.1023/A:1015201129331

27. Zhang, Q.-H.; Sheng, M.; Chen, G.; Aldrich, J. R.; Chamhan, K. R. Naturwissenschaften 2006, 93, 461-465. doi:10.1007/s00114-006-0132-z

28. Cavill, G. W. K.; Houghton, E.; McDonald, F. J.; Williams, P. J. Insect Biochem. 1976, 6, 483-490. doi:10.1016/0020-1790(76)90072-X

29. Dewhirst, S. Y.; Birkett, M. A.; Fitzgerald, J. D.; Stewart-Jones, A.; Wadhams, L. J.; Woodcock, C. M.; Hardie, J.; Pickett, J. A. J. Chem. Ecol. 2008, 34, 1575-1583. doi:10.1007/s10886-008-9561-9

30. Boevé, J.-L.; Braekman, J. C.; Daloze, D.; Honart, M.; Pasteels, J. M. Experientia 1984, 40, 546-547. doi:10.1007/BF01982322

31. Tschuch, G.; Lindemann, P.; Moritz, G. J. Chem. Ecol. 2008, 34, 742-747. doi:10.1007/s10886-008-9494-3

32. Meinwald, J.; Chadha, M. S.; Hurst, J. J.; Eisner, T. Tetrahedron Lett. 1962, 3, 29-33. doi:10.1016/S0040-4039(00)62038-5

33. Dossey, A. T.; Walse, S. S.; Rocca, J. R.; Edison, A. S. ACS Chem. Biol. 2006, 1, 511-514. doi:10.1021/cb600318u

34. Zhang, F.; Dossey, A. T.; Zachariah, C.; Edison, A. S.; Brüschweiler, R. Anal. Chem. 2007, 79, 7748-7752. doi:10.1021/ac0711586

35. Dossey, A. T.; Walse, S. S.; Edison, A. S. J. Chem. Ecol. 2008, 34, 584-590. doi:10.1007/s10886-008-9457-8

36. Pagnoni, U. G.; Pinetti, A.; Trave, R.; Garanti, L. Aust. J. Chem. 1976, 29, 1375-1381. doi:10.1071/CH9761375

37. Meinwald, J.; Jones, T. H.; Eisner, T.; Hicks, K. Proc. Natl. Acad. Sci. U. S. A. 1977, 74, 2189-2193. doi:10.1073/pnas.74.6.2189

38. Blum, M. S.; Wallace, J. B.; Duffield, R. M.; Brand, J. M.; Fales, H. M.; Sokoloski, E. A. J. Chem. Ecol. 1978, 4, 47-53. doi:10.1007/BF00988259

39. Shimizu, N.; Yakumaru, Z.; Sakata, T.; Shimano, S.; Kuwahara, Y. J. Chem. Ecol. 2012, 38, 29-35. doi:10.1007/s10886-012-0064-3 
40. Jones, T. H.; Blum, M. S. Tetrahedron Lett. 1981, 22, 4373-4376. doi:10.1016/S0040-4039(01)82960-9

41. Grant, H. G.; O'Regan, P. J.; Park, R. J.; Sutherland, M. D. Aust. J. Chem. 1980, 33, 853-878. doi:10.1071/CH9800853

42. Sakan, T.; Murai, F.; Isoe, S.; Hyeon, S. B.; Hayashi, S. J. Chem. Soc. Jpn., Pure Chem. Sect. 1969, 90, 507-511.

43. Sakan, T.; Murai, F.; Hayashi, Y.; Honda, Y.; Shono, T.; Nakajima, M.; Kato, M. Tetrahedron 1967, 23, 4635-4652. doi:10.1016/S0040-4020(01)92562-1

44. Sampaio-Santos, M. I.; Kaplan, M. A. C. J. Braz. Chem. Soc. 2001, 12, 144-153. doi:10.1590/S0103-50532001000200004

45. Stökl, J.; Hofferberth, J.; Pritschet, M.; Brummer, M.; Ruther, J. J. Chem. Ecol. 2012, 38, 331-339. doi:10.1007/s10886-012-0103-0

46. Lorenz, M.; Boland, W.; Dettner, K. Angew. Chem., Int. Ed. Engl. 1993, 32, 912-914. doi:10.1002/anie.199309121

47. Veith, M.; Lorenz, M.; Boland, W.; Simon, H.; Dettner, K. Tetrahedron 1994, 50, 6859-6874. doi:10.1016/S0040-4020(01)81338-7

48. Weibel, D. B.; Oldham, N. J.; Feld, B.; Glombitza, G.; Dettner, K.; Boland, W. Insect Biochem. Mol. Biol. 2001, 31, 583-591. doi:10.1016/S0965-1748(00)00163-6

49. Sugawara, F.; Matsuda, K.; Kobayashi, A.; Yamashita, K. J. Chem. Ecol. 1979, 5, 929-939. doi:10.1007/BF00990215

50. Pasteels, J. M.; Braekman, J. C.; Daloze, D.; Ottinger, R. Tetrahedron 1982, 38, 1891-1897. doi:10.1016/0040-4020(82)80038-0

51. Daloze, D.; Pasteels, J. M. J. Chem. Ecol. 1994, 20, 2089-2097. doi:10.1007/BF02066245

52. Feld, B. K.; Pasteels, J. M.; Boland, W. Chemoecology 2001, 11, 191-198. doi:10.1007/PL00001851

53. Kunert, M.; Søe, A.; Bartram, S.; Discher, S.; Tolzin-Banasch, K.; Nie, L.; David, A.; Pasteels, J.; Boland, W. Insect Biochem. Mol. Biol. 2008, 38, 895-904. doi:10.1016/j.ibmb.2008.06.005

54. Hübner, G.; Völkl, W.; Francke, W.; Dettner, K. Biochem. Syst. Ecol. 2002, 30, 505-523. doi:10.1016/S0305-1978(01)00137-5

55. Petersen, G.; Matthiesen, C.; Stolzenberg, N.; Zimmermann, N.; Hilgraf, R.; Lehmann, L.; Francke, W.; Wyss, U. Mitt. Dtsch. Entomol. Ges. 2001, 13, 51-55

56. Grasswitz, T. R.; Reese, B. D. BioControl 1998, 43, 261-271. doi:10.1023/A:1009987609371

\section{License and Terms}

This is an Open Access article under the terms of the Creative Commons Attribution License (http://creativecommons.org/licenses/by/2.0), which permits unrestricted use, distribution, and reproduction in any medium, provided the original work is properly cited.

The license is subject to the Beilstein Journal of Organic Chemistry terms and conditions: (http://www.beilstein-journals.org/bjoc)

The definitive version of this article is the electronic one which can be found at: doi:10.3762/bjoc.8.141 